\title{
Arachis hypogaea L. stem and leaf extract improves the sleep behavior of pentobarbital-treated rats
}

\author{
XIAO-YAN ZU ${ }^{1}$, GUANG-QUAN XIONG ${ }^{1}$, SHENG-RONG GENG $^{1}$, TAO LIAO $^{1}$, XIN LI $^{1}$ and ZHEN-YAZHANG ${ }^{2}$ \\ ${ }^{1}$ Institute for Farm Products Processing and Nuclear-Agricultural Technology, Hubei Academy of Agricultural Sciences, \\ Wuhan, Hubei 430064, P.R. China; ${ }^{2}$ Graduate School of Life and Environmental Sciences, \\ University of Tsukuba, Tsukuba, Ibaraki 305-8572, Japan
}

Received January 16, 2014; Accepted March 3, 2014

DOI: $10.3892 /$ br.2014.259

\begin{abstract}
This study was conducted to evaluate the sedative effects of Arachis hypogaea L. stem and leaf extract (AHSLE) and determine its effect pathways through $\gamma$-aminobutyric acid (GABA)-gated channels on male Sprague-Dawley rats treated with pentobarbital. AHSLE was obtained from $98^{\circ} \mathrm{C}$ water ( $3 \mathrm{~h}$, extracted twice). AHSLE and flumazenil (a GABA type A receptor antagonist) were administered to the rats orally, whereas pentobarbital sodium and muscimol (a GABA type A receptor agonist) were administered intraperitoneally (i.p.). The results demonstrated that AHSLE decreased sleep latency and increased sleep time in pentobarbital-treated rats $(50 \mathrm{mg} / \mathrm{kg}$, i.p.). The coadministration of AHSLE and muscimol $(0.05 \mathrm{mg} / \mathrm{kg})$ significantly increased sleep time and reduced sleep latency in pentobarbital-treated rats and these actions were significantly antagonized by flumazenil at a dose of $3.5 \mathrm{mg} / \mathrm{kg}$. These results indicated that AHSLE improved the sleep behavior in pentobarbital-treated rats, possibly through GABA-gated channel-related mechanisms.
\end{abstract}

\section{Introduction}

Arachis hypogaea L. stem and leaf extract (AHSLE) is a type of sleep aid used in China (1-3). $\gamma$-aminobutyric acid (GABA) receptors are known to play an important role in the modulation of barbiturate-induced sleep through interaction with GABAergic systems $(4,5)$. We previously reported (6) that AHSLE may lead to a significant decrease of glutamate/GABA ratio in corresponding brain areas in freely behaving rats. These findings raised the questions of whether AHSLE results in external manifestations of rat sleep behavior and whether AHSLE modulates barbiturate-induced sleep through GABAergic channels.

Correspondence to: Professor Zhen-Ya Zhang, Graduate School of Life and Environmental Sciences, University of Tsukuba, 1-1-1 Tennodai, Tsukuba, Ibaraki 305-8572, Japan

E-mail: oriswa@sina.com

Key words: Arachis hypogaea L. stem and leaf extract, sleep behaviors, pentobarbital-treated rats
In this study, in order to evaluate the sedative effects of AHSLE on rats and investigate its possible mechanisms of action, male Sprague-Dawley (SD) rats were employed and sleep was induced by pentobarbital. Sleep time and sleep latency were recorded following AHSLE administration. Muscimol, a GABA type $\mathrm{A}\left(\mathrm{GABA}_{\mathrm{A}}\right)$ receptor agonist, and flumazenil, a $\mathrm{GABA}_{\mathrm{A}}$ receptor antagonist, were used as positive controls, respectively.

\section{Materials and methods}

Plant, AHSLE and reagents. The Arachis hypogaea L. plants were collected from the shores of lake Yezi (Wuhan, Hubei, China) in August, 2011. The plant was authenticated by the Agriculture and Forestry Research Center of Tsukuba University, Japan. AHSLE powder was obtained as previously described $(6,7)$, comprising $1.92 \%$ protein and $65.31 \%$ carbohydrate. All the reagents used were of the highest available purity. Pentobarbital sodium was purchased from Rejuvenation Pharmaceutical Co., Ltd., (Fuzhou, China). Muscimol was purchased from Sigma (St. Louis, MO, USA). Flumazenil and other chemicals used were purchased from Wako Pure Chemical Industries, Ltd., (Osaka, Japan).

Animals. Male SD rats, aged 8 weeks and weighing 270 $\pm 30 \mathrm{~g}$, were provided by the Laboratory Animal Resource Center, University of Tsukuba, Japan. The animals were housed at ambient conditions of $25^{\circ} \mathrm{C}$, with 12-h light/dark cycles (light on at 08:00, light off at 20:00) and were given ad libitum access to food and water. All the animal experiments were conducted humanely, following approval from the Institutional Animal Experiment Committee of Tsukuba University, Japan and in accordance with the regulations for Animal Experiments and Fundamental Guidelines under the jurisdiction of the Japanese Ministries of Education, Culture, Sports, Science and Technology.

Experimental protocols. The experiments were performed between 20:00 and 24:00. Rats $(n=48)$ were employed and habituated in an animal lab for at least 7 days, then randomly divided into groups. In the 4 experiments, the number of rats in each group was 12, 9-12, 12 and 8, respectively. All the rats were reused after 2 weeks. The animals were fasted for 
Table I. Effects of pentobarbital, AHLAE and muscimol on rats.

\begin{tabular}{lcccc}
\hline Groups & $\begin{array}{c}\text { Dose } \\
(\mathrm{mg} / \mathrm{kg})\end{array}$ & $\begin{array}{c}\text { No. falling } \\
\text { asleep/total }\end{array}$ & $\begin{array}{c}\text { Sleep latency } \\
(\mathrm{min})\end{array}$ & $\begin{array}{c}\text { Sleep time } \\
(\mathrm{min})\end{array}$ \\
\hline Pentobarbital & 30 & $5 / 12$ & $31.67 \pm 1.15$ & $41.33 \pm 1.53$ \\
Pentobarbital & 50 & $12 / 12$ & $15.33 \pm 2.52$ & $48.33 \pm 9.07$ \\
AHSLE & 500 & $0 / 12$ & 0 & 0 \\
Muscimol & 10 & $0 / 12$ & 0 & 0 \\
\hline
\end{tabular}

The rats were fasted for $24 \mathrm{~h}$ prior to the experiment. AHSLE, muscimol and pentobarbital were administered and the number of rats falling asleep/total number, sleep latency and sleep time were recorded. The data of sleep latency and sleep time are presented as means \pm SD. AHSLE, Arachis hypogaea L. stem and leaf extract.
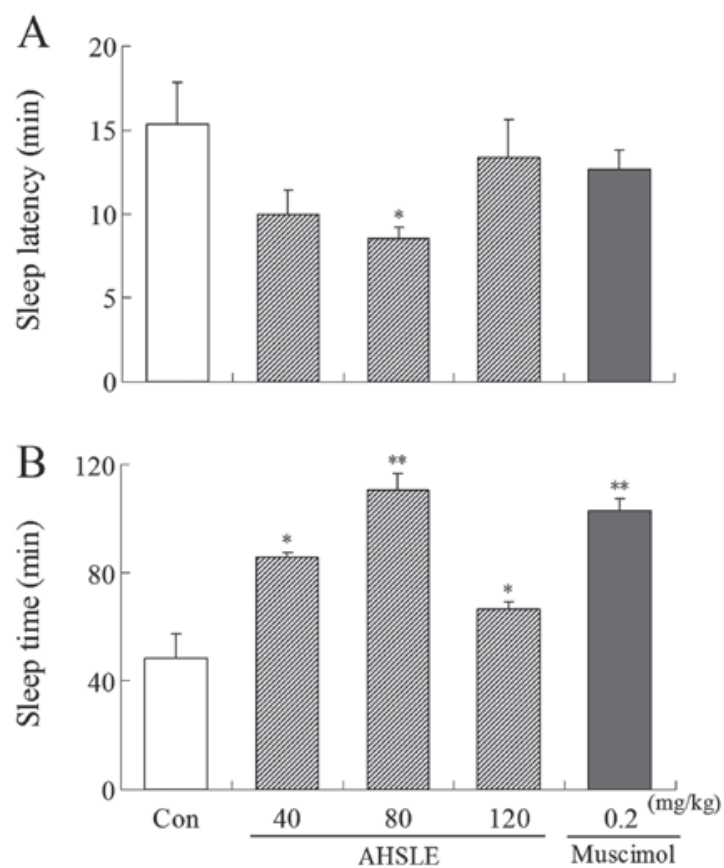

Figure 1. Effects of Arachis hypogaea L. stem and leaf extract (AHSLE) on sleep in pentobarbital-treated rats. Following administration of muscimol or AHSLE, pentobarbital $(50 \mathrm{mg} / \mathrm{kg})$ was intraperitoneally administered to the rats. (A) Sleep latency and (B) sleep time were recorded. ${ }^{*} \mathrm{P}<0.05$ and $^{* *} \mathrm{P}<0.01$, compared to the control (Con, open bar, without muscimol and AHSLE)

$24 \mathrm{~h}$ prior to the experiment. AHSLE in physiological saline and flumazenil in 10\% dimethyl sulfoxide were administered orally to the rats, whereas muscimol was administered intraperitoneally (i.p.). At $30 \mathrm{~min}$ following the administration of muscimol, flumazenil or AHSLE, pentobarbital sodium in physiological saline was administered i.p. to each rat to induce sleep. The animals that remained immobile for $>1 \mathrm{~min}$ were considered to be asleep. The sleep latency was recorded from the pentobarbital injection to $1 \mathrm{~min}$ after the loss of the righting reflex and the sleep time was recorded from $1 \mathrm{~min}$ after the loss of the righting reflex to recovery (8).

Statistical analysis. The obtained data were analyzed using two-tailed Student's t-test (version 2003, Microsoft excel) for comparisons and the results are expressed as means \pm SD.
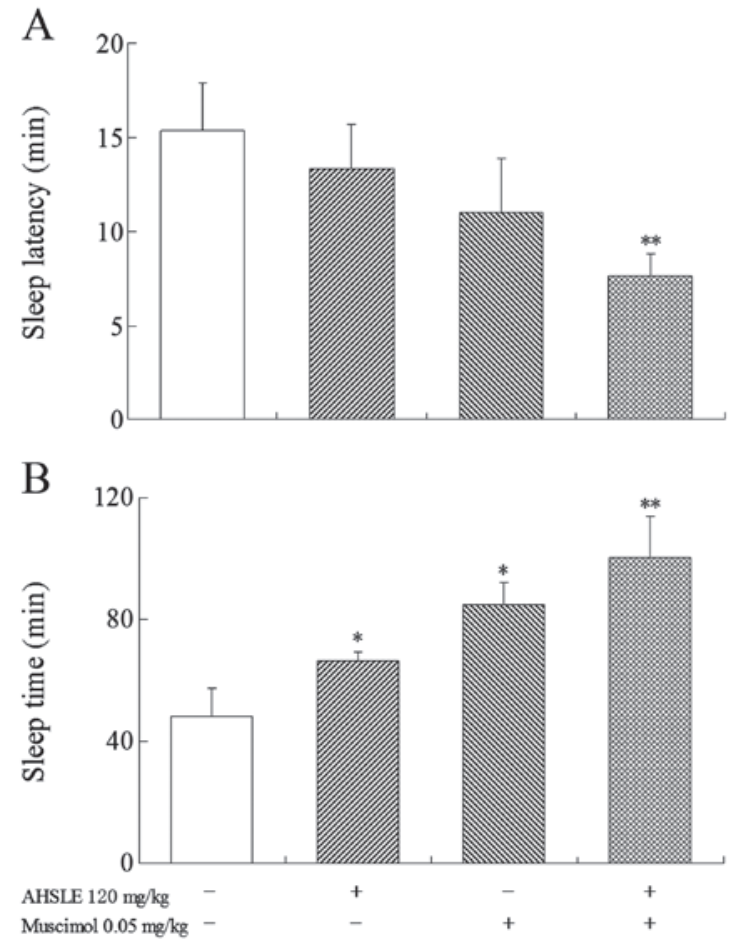

Figure 2. Effects of Arachis hypogaea L. stem and leaf extract (AHSLE) and muscimol on sleep in pentobarbital-treated rats. Following administration of AHSLE $(120 \mathrm{mg} / \mathrm{kg})$ and muscimol $(0.05 \mathrm{mg} / \mathrm{kg})$, pentobarbital $(50 \mathrm{mg} / \mathrm{kg})$ was intraperitoneally administered to the rats. (A) Sleep latency and (B) sleep time were recorded. Each column represents the mean $\pm \mathrm{SD}$. ${ }^{*} \mathrm{P}<0.05$ and ${ }^{* *} \mathrm{P}<0.01$, compared to the control (Con, open bar, without muscimol and AHSLE).
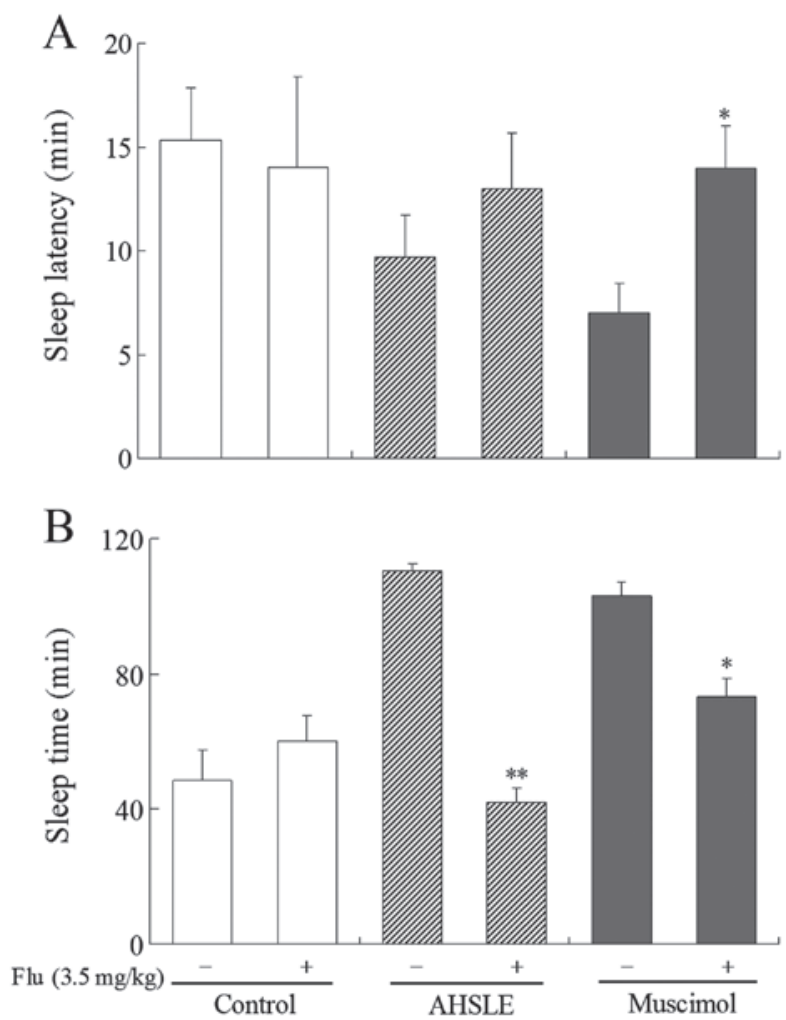

Figure 3. Effects of Arachis hypogaea L. stem and leaf extract (AHSLE) and flumazenil on sleep in pentobarbital-treated rats. Following administration of AHSLE $(80 \mathrm{mg} / \mathrm{kg}$ ), muscimol $(0.2 \mathrm{mg} / \mathrm{kg}$ ) or flumazenil (Flu, $3.5 \mathrm{mg} / \mathrm{kg}$ ), pentobarbital $(50 \mathrm{mg} / \mathrm{kg})$ was intraperitoneally administered to the rats. (A) Sleep latency and (B) sleep time were recorded. Data are presented as means $\pm \mathrm{SD}(\mathrm{n}=12)$. ${ }^{*} \mathrm{P}<0.05$ and ${ }^{* * *} \mathrm{P}<0.01$, compared to the group without Flu. 
$\mathrm{P}<0.05$ was considered to indicate statistically significant differences.

\section{Results}

Sedative effects of pentobarbital, AHSLE and muscimol. The results (Table I) revealed that pentobarbital induced sleep at a dosage of $50 \mathrm{mg} / \mathrm{kg}$. Muscimol was unsuccessful in inducing sleep. AHSLE alone, similar to muscimol, was unable to induce sleep directly, even at a high dose $(500 \mathrm{mg} / \mathrm{kg})$.

Effects of AHSLE on sleep in pentobarbital-treated rats. Following administration of muscimol or AHSLE, pentobarbital $(50 \mathrm{mg} / \mathrm{kg})$ was administered i.p. to the rats. AHSLE decreased sleep latency and prolonged sleep time in rats, particularly at a dose of $80 \mathrm{mg} / \mathrm{kg}$, following sleep induction by pentobarbital. Muscimol $(0.2 \mathrm{mg} / \mathrm{kg})$ as a positive control also induced a decrease in sleep latency and a prolongation of the total sleep time (Fig. 1).

Effects of AHSLE with muscimol on sleep in pentobarbital-treated rats. Prior to the administration of pentobarbital $(50 \mathrm{mg} / \mathrm{kg})$, low doses of muscimol $(0.05 \mathrm{mg} / \mathrm{kg})$ were used in the AHSLE (120 mg/kg)-treated groups (Fig. 2) to observe the direct association between the effects of muscimol and those of AHSLE. The results demonstrated that the pentobarbital-treated rats in the AHSLE+muscimol group exhibited significantly $(\mathrm{P}<0.01)$ increased sleep time and reduced sleep latency.

Effects of AHSLE with flumazenil on sleep in pentobarbital-treated rats. In pentobarbital $(50 \mathrm{mg} / \mathrm{kg})$-treated rats, AHSLE decreased sleep latency and also significantly prolonged sleep time at doses of $80 \mathrm{mg} / \mathrm{kg}$ (Fig. 1A and B). These actions were significantly antagonized by flumazenil, a benzodiazepine receptor antagonist, at a dose of $3.5 \mathrm{mg} / \mathrm{kg}$ (Fig. 3A and B). This antagonistic effect of flumazenil was also observed in rats that were administered muscimol.

\section{Discussion}

GABA is a type of inhibitory neurotransmitter amino acid in the brain, is primarily formed from glutamate via the action of glutamate decarboxylase (9) and may be used as a parameter to characterize the sleep-wake cycle (10). Pentobarbital is known to potentiate the effects of GABA through acting on the receptor sites of the GABA/benzodiazepine receptor-ionophore complex (11). The sedative effects may be assessed by decreases in the pentobarbital-induced sleep time and are possibly mediated through GABAergic systems (12). In this study, we aimed to determine whether sleep enhancement following AHSLE administration is mediated via the GABAergic systems.

The effects of different doses of AHSLE on rats with or without pentobarbital treatment were investigated. We observed that AHSLE was able to prolong pentobarbital-induced sleep at a lower dose $(40 \mathrm{mg} / \mathrm{kg})$; however, it was unable to induce sleep alone, even at a significantly higher dosage $(500 \mathrm{mg} / \mathrm{kg})$, which was similar to the effects of the $\mathrm{GABA}_{\mathrm{A}}$ receptor agonist muscimol. Moreover, AHSLE acted synergistically with muscimol in pentobarbital-treated rats. It was indicated that $\mathrm{GABA}_{\mathrm{A}}$ receptor channels may be involved in the AHSLE sedative effect pathways.

Previous studies demonstrated that flumazenil decreases sleep time and increases waking and sleep latency through suppressing the effects of $\mathrm{GABA}_{\mathrm{A}}$ receptors $(13,14)$. To further investigate the mechanisms underlying the potentiation of sedation caused by AHSLE, the effects of flumazenil on sleep induced by AHSLE in pentobarbital-treated rats were investigated. Flumazenil exerted no obvious effect when used alone, whereas it exhibited a significant antagonistic effect to that of AHSLE in pentobarbital-treated rats. These results demonstrated that the synergistic effects of AHSLE with pentobarbital or muscimol may antagonize the effects of flumazenil, a $\mathrm{GABA}_{\mathrm{A}}$ receptor antagonist. These findings also suggested that the activation of GABAergic systems induced by AHSLE may potentiate the activity of sedative agents.

We analyzed the essential oil components of AHSLE according to previous studies $(15,16)$ and found that it contained linalool (7), which may contribute to the sedative effects of AHSLE. The role of linalool requires validation by further experiments.

In conclusion, our results indicated that AHSLE enhanced the sedative effects in pentobarbital-treated rats and these effects were possibly mediated through GABA-gated channels and benzodiazepine receptors. AHSLE may be a candidate agent for the management of sleep disorders. However, the pharmacological effects of AHSLE derivatives, such as linalool, require further investigations.

\section{References}

1. Wang QC, Xu J and Shi M: Clinical efficacy of Groundnut leaves on insomnia treatments. Shanghai J Trad Chin Med 5: 8-10, 2001.

2. Hu PF, Fan RP, Li YP and Pang CY: Studies on pharmacological action of Luohuashengzhiye extract. Chin Trad Pat Med 23: 919-920, 2001 (In Chinese).

3. Wang YF, Li HF, Xu YF, Zhang YL, Xu DS, Xiao LM and Li XM: Clinical confirmation of preparation from the branch and leaf of peanut in treating insomnia. Shanghai J Trad Chin Med 5: 11-14, 2001 (In Chinese).

4. Doghramji PP: Trends in the pharmacologic management of insomnia. J Clin Psychiatry 67: 5-8, 2006.

5. Ma Y, Han H, Eun JS, Kim HC, Hong JT and Oh KW: Sanjoinine A isolated from Zizyphi Spinosi Semen augments pentobarbital-induced sleep behaviors through the modification of GABA-ergic systems. Biol Pharm Bull 30: 1748-1753, 2007.

6. Zu XY, Zhang ZY, Liu JQ, Hu HH, Xing GQ, Zhang Y and Guan D: Sedative effects of peanut (Arachis hypogaea L.) leaf aqueous extracts on brain ATP AMP, adenosine and glutamate/GABA of rats. J Biomed Sci Eng 3: 268-273, 2010.

7. Zu XY, Zhang ZY, Xiong GQ, Liao T, Qiao Y, Li YT, Geng SR and Li X: Sedative effects of Arachis hypogaea L. stem and leaf extracts on sleep-deprived rats. Exp Ther Med 6: 601-605, 2013.

8. Chu QP, Wang LE, Cui XY, Fu HZ, Lin ZB, Lin SQ and Zhang YH: Extract of Ganoderma lucidum potentiates pentobarbital-induced sleep via a GABAergic mechanism. Pharmacol Biochem Behav 86: 693-698, 2007.

9. Bown AW and Shelp BJ: The metabolism and functions of (gamma)-aminobutyric acid. Plant Physiol 115: 1-5, 1997.

10. Schousboe A, Westergaard N, Sonnewald U, Petersen SB, Yu AC and Hertz L: Regulatory role of astrocytes for neuronal biosynthesis and homeostasis of glutamate and GABA. Prog Brain Res 94: 199-211, 1992.

11. de Sousa FC, Pereira BA, Lima VT, Lacerda CD, Melo CT, Barbosa-Filho JM, Vasconcelos SM and Viana GS: Central nervous system activity of yangambin from Ocotea duckei Vattimo (Lauraceae) in mice. Phytother Res 19: 282-286, 2005. 
12. Ebert B, Thompson SA, Saounatsou K, McKernan R Krogsgaard-Larsen $\mathrm{P}$ and Wafford KA: Differences in agonist/antagonist binding affinity and receptor transduction using recombinant human gamma-aminobutyric acid type A receptors. Mol Pharmacol 52: 1150-1156, 1997.

13. Gaillard JM and Blois R: Differential effects of flunitrazepam on human sleep in combination with flumazenil. Sleep 12: 120-132, 1989.

14. Borbély AA, Akerstedt T, Benoit O, Holsboer F and Oswald I: Hypnotics and sleep physiology: a consensus report. European Sleep Research Society, Committee on Hypnotics and Sleep Physiology. Eur Arch Psychiatry Clin Neurosci 241: 13-21, 1991.
15. Guzman-Gutierrez SL, Gomez-Cansino R, Garcia-Zebadua JC, Jimenez-Perez NC and Reyes-Chilpa R: Antidepressant activity of Litsea glaucescens essential oil: identification of $\beta$-pinene and linalool as active principles. J Ethnopharmacol 143: 673-679, 2012.

16. Jalali Heravi M and Sereshti H: Determination of essential oil components of Artemisia haussknechtii Boiss. using simultaneous hydrodistillation-static headspace liquid phase microextraction-gas chromatography mass spectrometry. J Chromatogr A 1160: 81-89, 2007. 